\title{
Language specificity in lexical organization: Evidence from deaf signers' lexical organization of American Sign Language and English
}

\author{
VICKI L. HANSON \\ IBM Research Division, Thomas J. Watson Research Center, Yorktown Heights, New York \\ and Haskins Laboratories, New Haven, Connecticut \\ and \\ LAURIE B. FELDMAN \\ Haskins Laboratories, New Haven, Connecticut
}

\begin{abstract}
A sign decision task, in which deaf signers made a decision about the number of hands required to form a particular sign of American Sign Language (ASL), revealed significant facilitation by repetition among signs that share a base morpheme. A lexical decision task on English words revealed facilitation by repetition among words that share a base morpheme in both English and ASL, but not among those that share a base morpheme in ASL only. This outcome occurred for both deaf and hearing subjects. The results are interpreted as evidence that the morphological principles of lexical organization observed in ASL do not extend to the organization of English for skilled deaf readers.
\end{abstract}

Repetition priming studies have demonstrated an appreciation of morphological structure by users of spoken languages. Specifically, studies have shown that when a target word follows the presentation of either an inflectionally or a derivationally related prime word, responses to the target are facilitated. For example, responses to the target word sit will be facilitated when the target is preceded by the inflectionally related noun sits or by the derivationally related verb sitter (Fowler, Napps, \& Feldman, 1985; Stanners, Neiser, Hernon, \& Hall, 1979). Note that the triad sit, sits, and sitter share the base morpheme sit, but differ with respect to final morpheme (specifically, $\theta,-s$, -er). Therefore, they represent a set of morphologically related words.

In contrast, no significant facilitation is obtained for targets following the presentation of orthographically related (but morphologically unrelated) items (Feldman, 1987; Feldman \& Moskovljević, 1987; Murrell \& Morton, 1974; Napps \& Fowler, 1987). Thus, for example, there is no demonstrable facilitation for the target sit following the presentation of the word site. Sit and site, although formally (visually) similar, do not share a base morpheme.

This research was supported by Grant NS-18010 from the National Institute of Neurological and Communicative Disorders and Stroke and by Grant HD-01994 from the National Institute of Child Health and Human Development. We are grateful to Michael Karchmer and Patrick Cox at Gallaudet University for supporting this work. We wish to thank Carol Padden and Carol Fowler for their very constructive comments on earlier drafts of this manuscript, and to thank the reviewers for many helpful suggestions. We also wish to thank Deborah Kuglitsch and Terry Ullery for helping to test the subjects. This research was presented at the meeting of the Psychonomic Society, Seattle, WA, November, 1987 Requests for reprints should be sent to Vicki L. Hanson, IBM Watson Research Center, P.O. Box 218, Yorktown Heights, NY 10598.
This outcome has been interpreted as evidence that formal similarity alone cannot account for the pattern of facilitation produced by the repetition priming paradigm.

Morphologically related words are obviously also related semantically and sometimes associatively. Facilitation due to semantic or associative priming has been experimentally demonstrated to persist only at short intervals between prime and target, specifically, at lags of 1 or 2 items (Dannenbring \& Briand, 1982; Henderson, Wallis, \& Knight, 1984; Ratcliff, Hockley, \& McKoon, 1985). In contrast, the studies reporting effects of morphological priming have found these effects to be more longlasting. In fact, these effects have been obtained at lags as long as 48 items (Fowler et al., 1985).

The finding that facilitation is produced under conditions of morphological priming has been interpreted as evidence that morphologically related words are stored close together in the internal lexicon. The particular form of this organization has been debated: it has variously been characterized as a base entry with associated tags for related words (Murrell \& Morton, 1974; Stanners et al., 1979; Taft \& Forster, 1975), as fully formed words that are linked to relatives (Lukatela, Gligorijević, Kostić, \& Turvey, 1980) or as some combination of the two (Fowler et al., 1985). Despite discussion about how best to represent this lexical knowledge, the general claim that facilitation in the repetition priming task reflects a morphological principle of organization within the lexicon is widely accepted.

In the present study, we examined lexical organization by deaf bilinguals of American Sign Language (ASL) and English. We were interested in whether the lexical organizations of the two languages are the same or whethel 
there is language specificity, such that signs in ASL are organized in accord with relationships inherent in ASL morphology, whereas words in English are organized in accord with relationships inherent in English morphology.

ASL is the common form of communication used by members of deaf communities across the United States and parts of Canada. Deaf children may acquire ASL as a first language either through contact with the deaf community or from deaf parents. It is a primary visual-gestural system, autonomous from other languages. It is not based on or derived from any form of English. Contrast, for example, the lexical structuring for the word SIT in English and ASL. In English, base lexical items are composed of sequentially structured phonemic segments (e.g., $/ s / / I / / t /)$. In ASL, however, base lexical items are composed of the co-occurring formational parameters of handshape, movement, and place of articulation (Stokoe, Casterline, \& Croneberg, 1965). For example, in ASL the sign for SIT is produced, as shown in Figure 1, with $\mathrm{H}$-handshapes, the place of articulation in neutral space in front of the signer, and the movement of the dominant hand being a single sweeping motion contacting the nondominant hand.

One of the intriguing aspects of ASL structuring is that, in contrast to English, in which morphological processes generally operate by the affixing of a sequence of morphemes (composed of phonemic segments; e.g., -ing, -ed, -er) to base morphemes, morphological processes in ASL may involve embedding the base morpheme within a specific pattern of movement, such that the base morpheme of the sign and the inflectional or derivational morphemes of the sign co-occur. As an example, one of the many morphological relationships marked in ASL is a noun-verb distinction. According to the linguistic analysis of derivationally related noun-verb pairs such as CHAIR-SIT (Supalla \& Newport, 1978), the sign for CHAIR and the sign for SIT share an underlying representation (base morpheme) in which information about such features as handshape, place of articulation, movement, and direction of movement are stored. The surface forms of these signs are presumed to be derived by modulations applied to this common base. As shown in Figure 1, the

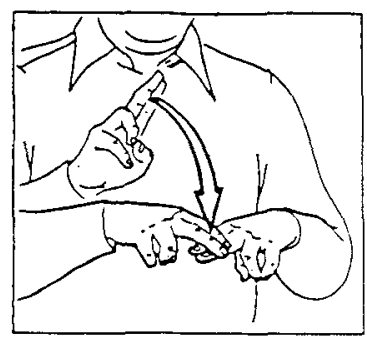

SIT

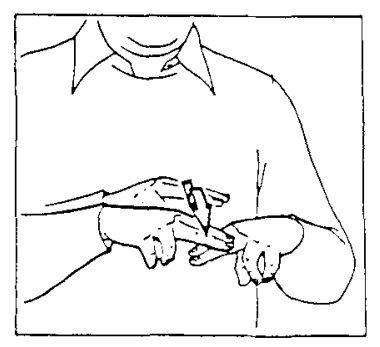

CHAIR
Figure 1. An example of a derivationally related noun-verb pair in ASL: the signs for SIT and CHAIR. (From American Sign Language: $A$ teacher's resource text on grammar and culture, $p .105$, by C. Baker and D. Cokely, 1980, Silver Spring, MD: T.J. Publishers. Copyright 1980 by T.J. Publishers. Reprinted by permission.) verb SIT has a single, relatively free movement, whereas the noun CHAIR has the same movement in a duplicated and restrained (or smaller) form.

Although morphological processes of ASL have been linguistically described, it is unclear under what conditions, if any, these relationships influence signers' lexical organization. Earlier work has shown that deaf signers decompose morphologically complex signs into their base and morphological marker when remembering single signs and signed sentences (Hanson \& Bellugi, 1982; Poizner, Newkirk, Bellugi, \& Klima, 1981). For example, in a short-term memory task, Poizner, Newkirk, et al. (1981) presented short lists of inflected signs to deaf subjects. In recalling these lists of signs, the subjects would sometimes recall a base sign with an inflection from a different item in the test. For example, when presented with lists of signs containing the morphologically complex signs corresponding to the English phrases TAKE ADVAN TAGE OF THEM and PAY ME, a typical error was recalling the signs for TAKE ADVANTAGE OF ME and PAY THEM. This outcome was taken as evidence that the signers were remembering the base entry and the inflectional tags separately. This result, however, does not address the issue of how these base signs (or composites of signs) are organized in the signers' lexicon.

If, as occurs in experimental tasks conducted with English materials, the underlying morphological structure is abstracted from signs, then we would expect the lexical organization of ASL to reflect morphological relationships. In Experiment 1 we examined this question. As the test case, we chose to examine the case of morphologically related noun-verb pairs, because this morphological relationship has been well studied (Supalla \& Newport, 1978). Since the morphological structuring in ASL, as in the case of the noun-verb pairs used in Experiments $I$ and 2 , represents a departure from how morphological relationships are marked in English, we were interested in whether a morphological distinction that is marked by a global feature (in this case, movement) can be abstracted in a manner functionally equivalent to the way in which a user of English abstracts the underlying morphological structure of that language. Given that ASL had been shown in the linguistic (see Padden, 1987, for a discussion) and psycholinguistic (see, e.g., Poizner, Klima, \& Bellugi, 1987) research to date to operate according to the same principles as other natural languages, we expected that evidence of lexical organization based on ASL morphology would be obtained. If so, we could proceed to the question of primary interest, which was whether deaf readers' lexical organization of English reflects relationships inherent to ASL.

In order to examine how morphological relatives are stored in the ASL lexicon of deaf signers, a task requiring subjects to respond in a "sign mode" was necessary. For this purpose we developed a sign decision task. In this task, as in most repetition priming studies, subjects were presented with printed target and prime items. Rather than deciding whether these items were words in English, 
however, in the sign decision task the subjects were required to indicate the number of hands that they used to produce the sign for each word. Therefore, as each English word was presented, they had to think of the sign for the word and then make a decision based on the physical form of that sign. Note that it would not have been possible to perform this task based simply on the English forms of the words. Thus, the sign decision task is not an English reading task; it is a task that uses the subjects' knowledge of ASL. Nevertheless, as in a lexical decision task, items were presented individually, the subjects were asked to respond as quickly and as accurately as possible, and reaction time (RT) was measured.

The analysis of subjects' accuracy in the sign decision task is not as straightforward as the analysis of accuracy in a lexical decision task. There are, for example, dialectal differences that cause signers from different parts of the country to produce different signs for a given English word. For this reason, following the sign decision task the subjects were given an unspeeded paper-and-pencil version of the task in which they were again asked to indicate, this time in writing, the number of hands that they used to produce the sign for each word listed. The correctness of each subject's answers in the timed sign decision task was then determined relative to each subject's own stated sign productions.

Assuming that sign priming can be demonstrated for deaf subjects, we can ask whether deaf bilinguals also organize their English lexicons according to morphological relatedness among signs. In Experiment 2, we investigated lexical organization of English by deaf bilinguals. In both Experiments 1 and 2 we used a set of words that are morphologically related only in ASL and a set that are morphologically related in both ASL and English. The same set of ASL-only words was used in both experiments. The words in the English + ASL sets in the two experiments were not identical, although there was substantial overlap.

The ASL-only stimuli were derivationally related nounverb pairs that shared a base morpheme and were morphologically distinguished by a change in movement superimposed throughout the production of the sign. Examples are EAT/FOOD, SAIL/BOAT, DRIVE/CAR, $\mathrm{LOCK} / \mathrm{KEY}$, and SHOOT/GUN. Note that these items are also associatively related.

The English + ASL set of stimuli were words that are morphologically related in both English and ASL. Examples of pairs from this condition are JUMP/JUMPING, TEACHER/TEACH, and CREATING/CREATE. For these pairs, the morphological relationship in ASL was sometimes structurally different than that of the ASL-only set. For example, in pairs such as TEACHER/TEACH, the morphological marker used sequential rather than simultaneous structuring. Note that although these pairs are semantically related, they are not associatively related: when given the word teacher, subjects are much more likely to free-associate student than to free-associate teach.

To guard against influences of associative and semantic priming, in the present study we used an average lag of 10 items, a lag too great to produce such priming (Dannenbring \& Briand, 1982; Henderson et al., 1984; Ratcliff et al., 1985). Consequently, any facilitation obtained in the present priming study could convincingly be attributed to morphological, not associative or semantic, priming.

To summarize, in Experiment 1 we used a sign decision task to examine whether signers' lexical organization of ASL is based on relationships inherent to ASL morphology. The experimental materials consisted of target words and their morphologically related primes. The analyses focused on decision latencies and errors to targets facilitated by the prior presentation of a related prime, in order to investigate morphological priming under conditions in which subjects are responding based on their knowledge of ASL. In Experiment 2, the same materials were presented to deaf and hearing subjects in a lexical decision task of English. As in Experiment 1, the analyses focused on decision latencies and errors to targets preceded by morphologically related primes. In Experiment 2, the subjects responded based on their knowledge of English. The purpose of Experiment 2 was, therefore, to examine whether deaf signers' organization of English words is based on relationships inherent to English or to ASL morphology. In other words, in Experiment 2 we investigated the role of the morphological structure of ASL in the lexical organization of English.

\section{EXPERIMENT 1}

\section{Method}

Subjects. The subjects were 19 deaf students from Gallaudet University. All were prelingually and profoundly deaf, with hearing losses of $85 \mathrm{~dB}$ or greater in the better ear. Twelve of these subjects were native signers of ASL and another 2 came from deaf families (i.e., they had older deaf siblings and deaf grandparents). The remaining subjects had acquired ASL before they entered school and reported ASL to be their preferred means of communication with deaf and hearing friends. All were paid volunteers for this 15-min experiment. As measured by the comprehension subtest of the Gates-MacGinitie Reading Tests (1978, Level F, Form 2), their median reading grade level of English was 7.4 (range $=12.9+$ to $3.3, N=16$ ).

Stimuli. The experimental materials consisted of 28 pairs composed of a target word and a morphologically related prime. Two sets of materials, distinguished by the language in which they were morphologically related, were created: ASL-only and English + ASL. Each set included 14 pairs.

In the ASL-only set, all paired items were derivationally related noun-verb pairs. For example, the target word CHAIR was paired with the derivationally related prime word SIT. As described earlier and shown in Figure 1, CHAIR and SIT share the same handshape and place of articulation, but differ in their movement. SIT has the single motion of a verb, whereas CHAIR has the more constrained double movement of a noun. These word pairs were taken from the list of noun-verb pairs in Supalla and Newport (1978). The experimental set represents all the words that fit within the following experimental constraints: (1) the items in the noun-verb pairs correspond to different English words (thus excluding pairs such as SKI/SKI); (2) there is an unambiguous English interpretation for each item in a noun-verb pair (thus excluding pairs such as CIGARETTE/SMOKE, in which SMOKE could be correctly translated as the verb, or, in this study, incorrectly translated as the noun); 
and (3) each item does not require multiple English words to translate the ASL sign (thus excluding pairs such as BABY/ROCK BABY IN ARMS). ${ }^{\prime}$

In the English + ASL set, base words served as targets and words inflectionally and derivationally related to these base words served as primes. The pairs were subject to the following constraints: in both target and prime, the stem undergoes no change in spelling and no change in pronunciation in English. For example, in this set the target word wish was paired with the morphologically related prime word wishing. A complete list of the stimuli is given in the Appendix.

Two test orders were created. Each included equal numbers of primed and unprimed trials for both ASL and English + ASL items. The lists were constructed so that targets preceded by morphological primes in one list were preceded by unrelated words in the second list, and vice versa. Each subject saw only one test order, thus responding to each target only once, in either a primed or an unprimed context.

Each list consisted of one block of 118 trials, presented in a fixed, order. Prime and target items were separated by an average of 10 intervening items (the range was 8 to 12). Filler items were included to preserve appropriate lags. These filler items were words chosen to maintain approximately equal numbers of one- and two-handed sign responses.

Procedure. The start of each trial was signaled by a $250-\mathrm{msec}$ fixation point $(+)$ presented in the center of a CRT display, followed by a 250 -msec blank interval. The letter string was then presented in the center of the CRT display. The stimulus remained in view until the subject pressed a response key or until $5 \mathrm{sec}$ had elapsed. Feedback was given on each trial. The feedback was the subject's RT (in msec) for that trial. If the subject failed to respond within the 5-sec time limit, the words TOO SLOW appeared as feedback. The feedback, displayed for $250 \mathrm{msec}$, was centered six lines below the fixation point. Following the message, there was a $1-\mathrm{sec}$ interval before the start of the next trial. Prior to testing with the experimental stimuli, the subjects received one practice block of 15 trials.

The subjects were told that on each trial they would see a letter string and that their task was to decide, as quickly and as accurately as possible, whether they made the sign for that word with one or two hands. There were two response keys: one was labeled 1 and the other 2. The subjects were instructed to sit with one index finger resting on each key and to respond as quickly as possible. They were also informed about the nature of the feedback. The experimenter was a deaf native signer, a former Gallaudet student, who communicated with the subjects by signing.

Following completion of the sign decision task, each subject was given a piece of paper on which were typed 49 words from the test order that the subject had been given. These 49 words consisted of the 28 target items ( 14 from each set), the 14 morphologically related primes that had occurred in the test order for that subject, and 7 of the 14 unrelated primes from that test order. Each word was typed in uppercase letters, with a line preceding it. The following instructions were typed at the top of the paper:

Below are listed the words you just saw in the sign decision task on the computer. Different people sometimes sign a few of these words in different ways. For each word, please indicate if YOU sign the word with one hand or two hands. For example:

\section{BABY}

1 EYE

\section{Results}

The subjects' own judgments in the paper-and-pencil task were used to determine the correct answer for each item in the sign decision task. Thus, the correct response in the sign decision task was conditionalized on each sub- ject's answers in the paper-and-pencil task. RTs were stabilized by eliminating responses whose RTs differed by more than two standard deviations from a subject's mean. The resulting mean RTs and mean percentage errors are shown in Table 1.

An analysis of variance was performed on the latencies for the within-subject variables of prime condition (primed vs. unprimed) and language of morphological relation (English + ASL vs. ASL-only). The analysis for RTs revealed a significant main effect of prime condition $[F(1,18)=$ $\left.5.76, M S_{c}=31,978.23, p<.03\right]$. On an items analysis, with language of morphological relation being treated as a between-items factor, this main effect of prime condition was also significant $\left[F(1,26)=14.08, M S_{\mathrm{e}}=\right.$ $10,835.81, p<.02]$. There was no effect of language of morphological relation $\left[F(1,18)=2.90, M S_{\mathrm{c}}=\right.$ $17,249.42, p>.10$, for subjects; $F<1$ for items]. The interaction of the two variables was not significant ( $F \mathrm{~s}<1$ for both subjects and items). No significant effects were revealed in the error analyses, (all $F_{S}<1$ ).

Finally, a $t$ test revealed that the $125-\mathrm{msec}$ facilitation with the ASL-only set was significant $[t(18)=2.15$, $p<.05$, for subjects; $t(13)=3.02, p<.01$, for items $]$. This outcome is critically important in the interpretation of both this experiment and Experiment 2, and will be treated in the Discussion of Experiment 2.

\section{Discussion}

In Experiment 1, significant facilitation for morphologically related items was obtained with materials of both the English + ASL set and the ASL-only set. Interpretation of the facilitation for English + ASL is ambiguous as to whether lexical organization is based on relationships derived from English or from ASL. However, the fact that comparable facilitation was obtained for the ASLonly set indicates that lexical organization can be based on principles of ASL. The obtained facilitation for the ASL-only stimuli cannot be explained as being due to associative priming, as the lags introduced in the present study were too great to permit such priming (Ratcliff et al., 1985; see also Dannenbring \& Briand, 1982). This pattern of results suggests that users of ASL tend to organize their lexicons according to morphological relationships.

It is worthy of note that the results were obtained using prime-target pairs in which the morphological relationship was indicated by a process quite different from the morphological processes that generally operate in English. In Experiment 1, the noun-verb distinction of the pairs was indicated by a change in the movement throughout the sign production.

Table 1

Mean Reaction Times (RT, in msec) and Percentage Errors (PE) for Deaf Subjects in the Sign Decision Task of Experiment 1

\begin{tabular}{lrrrrr} 
& \multicolumn{2}{c}{ English + ASL } & & \multicolumn{2}{c}{ ASL-Only } \\
\cline { 2 - 3 } \cline { 5 - 6 } & RT & PE & & RT & PE \\
\cline { 5 - 6 } Unprimed & 1085 & 13.5 & & 1163 & 12.8 \\
Primed & 1013 & 12.8 & & 1038 & 9.0 \\
\hline
\end{tabular}


Arguably, the effect here could be visual, based on the visual similarity of prime and target signs for the pairs in the ASL-only set. This argument is difficult to support, however. This argument for facilitation based on the visual similarity of signs would be analogous to an argument based on the visual (orthographic) similarity of printed words or the phonetic similarity of spoken words. Evidence from different paradigms (e.g., lexical decision, recognition) has established, however, that formal similarity, in the absence of a shared base morpheme, does not facilitate responding for any but the briefest intervals (Feldman \& Moskovljević, 1987; Hanson \& Wilkenfeld, 1985; Kirsner, Dunn, \& Standen, 1987; Murrell \& Morton, 1974; Napps \& Fowler, 1987). As noted earlier, the linguistic and psychological evidence gives no reason to suggest that ASL signs would be processed differently (e.g., Padden, 1987; Poizner et al., 1987). For example, in early research on ASL there was much discussion of the role that iconic aspects of signs would play in signers' processing of signs. This turned out not to be relevant. Signers, in short-term memory situations, have been found to process signs as linguistic events, not as iconic "pictures" (Poizner, Bellugi, \& Tweney, 1981) or as unanalyzed "wholes" (Hanson \& Bellugi, 1982; Poizner et al., 1981). There is little reason, therefore, to expect that it is the visual/motoric similarity of the signs for words in the ASL-only set that is responsible for producing the response facilitation observed in Experiment 1.

Given that the ASL lexicon of signers suggests a principle of organization based on the morphology of ASL, how is their lexicon of English organized? In Experiment 2 we investigated whether the English lexicon is influenced by the morphological relationships of ASL.

From the bilingual literature, there is reason to expect that ASL organization would not influence the organization of a signer's English lexicon. For example, in studies that have looked at whether a word in one language activates its translation in another language, influences of one language on the processing of the other have not been obtained, provided that the experiment has not been set up to encourage such translation (Kirsner, Brown, Abrol, Chadha, \& Sharma, 1980; Kirsner, Smith, Lockhart, King, \& Jain, 1984; Scarborough, Gerard, \& Cortese, 1984; Watkins \& Peynircioğlu, 1983; see also Beauvillain \& Grainger, 1987). The lexical decision task of Experiment 2 is not one that requires translation from one language into another; that is, it does not test whether the printed words SIT and CHAIR are translated into their corresponding ASL signs.

Another finding from the bilingual literature would lead us to expect that ASL principles would not guide the organization of the English lexicon for the subjects used in the present study. Research with bilinguals has found evidence for translation into the first language only for readers who have poor mastery of the second language (Kroll \& Borning, 1987). The deaf subjects in the present study had a fairly good mastery of their second language,
English. As we will see, the deaf subjects in Experiment 2 were reading, on average, at the 10th-grade level.

The present study differed from these previous bilingual studies, however, in terms of the radically different structuring of the two languages studied. Consider the difference between a bilingual of two spoken languages and a bilingual of ASL and English. The building blocks of two spoken languages are similar; that is, the phonological and morphological segments in both languages are articulated by gestures of the vocal tract. This is true whether the two languages are similar, such as English and Spanish, or relatively different, such as English and Chinese. In contrast, the building blocks of ASL and English are quite different. Whereas in ASL the phonological ${ }^{2}$ and morphological elements are visible gestures articulated by the hands, face, and body of the signer, in English these elements are audible gestures articulated by the vocal tract of the speaker. Moreover, not only do the building blocks differ for ASL and English, but the building blocks of English are not readily accessible to the deaf individual. If tests of the speaking and lipreading skills of deaf individuals are used as an indicator, it is apparent that the underlying phonemic representation of English words is not always well mastered by deaf individuals (e.g., Smith, 1975).

Accordingly, the differences in processing in sign and speech may be so great that for the deaf individual who has ASL as a first language and has established mental processing based on sign language parameters, language operations will continue to be carried out in ASL mode regardless of the language of input. This is the primarylanguage notion of Shand (1982; Shand \& Klima, 1981). This notion predicts that English words would be translated into their corresponding ASL signs regardless of task requirements. As a consequence, the lexical organization revealed in an English task would be expected to reflect ASL organizational principles.

In summary, arguments can be made on the basis of the existing literature to support either the presence or the absence of an influence of ASL lexical organization on the reading of English. In Experiment 2, we sought to resolve this issue. We employed a standard lexical decision (word/nonword) task to examine whether deaf signers exploit morphological relationships among ASL words while reading English materials. Two groups of subjects were tested: a group of deaf college students who reported ASL to be their first language, and a control group of hearing college students. On the basis of the English repetition priming literature, we would expect hearing subjects to show facilitation to target words primed by morphological relatives in the English + ASL set, since both inflectional and derivational relationships have been shown to facilitate responding (Fowler et al., 1985; Stanners et al., 1979). Because only an English relationship could benefit the hearing subjects, morphological priming should be absent for items that were morphologically related only in ASL. Due to the rapid decay of as- 
sociative priming, any associative relatedness between pairs in the ASL-only set would not facilitate responding under the lag conditions of Experiment 2. Of particular interest was whether the deaf subjects would show significant priming in both the ASL-only and English + ASL sets or only in the latter set. Experiment 1 demonstrated significant priming in both sets. If, due to experiences in sign, deaf signers organize their English lexicons along the morphological principles that apply to ASL, then in Experiment 2 we would expect to see facilitation in English reflecting morphological relationships of ASL. Specifically, both stimulus sets should show facilitation. By contrast, if deaf readers maintain distinct morphological principles in their English and ASL lexicons, then words that are related in their ASL lexicon need not be linked in their English lexicon. In this case, we would expect to see facilitation restricted to the English + ASL set.

\section{EXPERIMENT 2}

\section{Method}

Subjects. The deaf subjects for this study were 19 paid volunteers from Gallaudet University. All were prelingually deaf, with onset of deafness occurring prior to 1 year of age. Seventeen of these subjects had deaf parents; the other 2 subjects had learned to sign prior to entering school. Furthermore, all had a profound hearing loss of $85 \mathrm{~dB}$ or greater, pure tone average. Available reading achievement test scores, measured on the comprehension subtest of the Gates-MacGinitie Reading Tests (1978, Level F, Form 2), indicated a median reading level of grade 10.2 (range = $12.9+$ to $6.0, N=14$ ). This sample group of subjects, therefore, represented a relatively skilled subset of the population of deaf readers.

The hearing subjects for this study were 20 undergraduates at the University of Delaware who participated in partial fulfillment of the research requirements in an introductory psychology course. All were native speakers of English with normal or corrected-tonormal vision.

Stimuli. The experimental materials overlapped those of Experiment 1 . The ASL-only set contained the 14 prime-target pairs used in Experiment 1. The 14 prime-target pairs in the English + ASL set differed from those of Experiment 1, but were selected according to the same criteria. ${ }^{3} \mathrm{~A}$ complete list of the stimuli is given in the Appendix.

The experimental materials consisted of two lists of 118 stimuli: Both lists were composed of equal numbers of words and pseudowords. Each target (word or pseudoword) was separated from its prime by an average of 10 intervening items (range, 7-13). Half of the items in each list were preceded by morphologically related primes and half were not. Across lists, each target was preceded by its related prime. ${ }^{4}$ Each subject saw only one of the experimental lists, which ensured that the target word was viewed only once by a subject, in either a primed or an unprimed context, and that all subjects viewed both primed and unprimed targets.

Pseudowords were created by changing one or two letters in the real words. Consequently, for English + ASL pseudowords, prime and target were physically similar (e.g., LELPER/LELP for HELPER/HELP), whereas for ASL-only pseudowords, there was no similarity of prime and target (e.g., GOOM/OIT for FOOD/EAT).

Procedure. The procedure was identical to that of Experiment 1, except for instructions as to task and some change in feedback. The feedback was the subject's RT (in msec) for the trial that, if the subject had made an error on that trial, was preceded by a minus sign.

The subjects were told that on each trial they would see a letter string and that their task was to decide, as quickly and as accurately as possible, whether or not the string was a real English word. The two responses were associated with different keys: the right-hand one was labeled YES and the left-hand one was labeled NO. The subjects were instructed to sit with one index finger resting on each key and to respond as quickly as possible. They were also informed about the nature of the feedback. For the deaf subjects, the experimenter was a deaf native signer, a former Gallaudet student, who communicated with the subjects by signing. For the hearing subjects, the experimenter was an undergraduate at the University of Delaware. Prior to testing with the experimental stimuli, the subjects received one practice block of 15 trials. The total duration of the experiment was about $15 \mathrm{~min}$.

\section{Results}

A preliminary items analysis indicated that the target word STRUM was missed by the hearing subjects on $80 \%$ of its presentations and by deaf subjects on $100 \%$ of its presentations. For that reason, this item was eliminated from all analyses for both the deaf and hearing subjects. As in Experiment 1, RTs that deviated by more than two standard deviations from the cell means were eliminated from analysis. The resulting mean correct RTs and the mean percentage errors are shown in Table 2 . There were no significant interactions involving subject group in any of the analyses reported below (all $p s>.05$ ). Thus, the same pattern of results was obtained for both the hearing and the deaf subjects.

For word latencies, an analysis of variance on the within-subjects factors of prime condition (unprimed vs. primed) $\times$ language of morphological relation (English + ASL vs. ASL-only) and the between-subjects factor of group (deaf vs. hearing) indicated a significant inter-

Table 2

Mean Reaction Times (RT, in msec) and Percentage Errors (PE) to Words and Nonwords for Hearing and Deaf Subjects in the Lexical Decision Task of Experiment 2

\begin{tabular}{|c|c|c|c|c|c|c|c|c|}
\hline & \multicolumn{4}{|c|}{ English + ASL } & \multicolumn{4}{|c|}{ ASL-Only } \\
\hline & \multicolumn{2}{|c|}{ Hearing } & \multicolumn{2}{|c|}{ Deaf } & \multicolumn{2}{|c|}{ Hearing } & \multicolumn{2}{|c|}{ Deaf } \\
\hline & $\mathbf{R T}$ & PE & RT & $\mathrm{PE}$ & RT & PE & RT & $\mathrm{PE}$ \\
\hline \multicolumn{9}{|c|}{ Words } \\
\hline Unprimed & 525 & .7 & 519 & 2.2 & 546 & 2.4 & 558 & 2.2 \\
\hline Primed & 484 & .7 & 479 & .0 & 552 & 3.4 & 550 & .7 \\
\hline \multicolumn{9}{|c|}{ Nonwords } \\
\hline Unprimed & 635 & 15.3 & 667 & 4.1 & 608 & 2.5 & 621 & 2.7 \\
\hline Primed & 627 & 10.0 & 627 & 10.7 & 632 & 9.9 & 633 & 11.7 \\
\hline
\end{tabular}


action of condition $\times$ language of morphological relation $\left[F(1,37)=6.91, M S_{\mathrm{e}}=2,143.20, p<.02\right]$. This significant interaction also generalized across stimuli, as indicated by the items analysis with language as a betweenitems factor, $\left[F(1,48)=5.61, M S_{\mathrm{e}}=1,366.53, p<\right.$ .03].

Separate post hoc analyses on condition $\times$ group for each language revealed significant facilitation for English + ASL materials $\left[F(1,37)=14.87, M S_{\mathrm{e}}=2,152.03\right.$, $p<.001$, for subjects; $F(1,26)=13.23, M S_{\mathrm{e}}=$ $1,629.68, p<.002$, for items], but not for ASL-only materials $[F \mathrm{~s}<1$ for both subjects and items analyses]. There was no interaction with subject group in either of these post hoc tests (both $F_{\mathrm{s}}<1$ ). Most critically, although the deaf subjects in Experiment 1 had shown a significant $125-\mathrm{msec}$ facilitation with the ASL-only set, in Experiment 2, the deaf subjects showed only a 9-msec nonsignificant decrease in RTs $(t s<1$ for both subjects and items). Thus, for both subject groups, significant facilitation was obtained following English + ASL morphological primes, but not following ASL-only morphological primes.

Finally, the overall analysis of variance on RTs also revealed significant main effects of prime condition $\left[F(1,37)=10.54, M S_{\mathrm{e}}=1,636.48, p<.005\right.$, for subjects; $F(1,48)=9.17, M S_{\mathrm{e}}=1,366.53, p<.005$, for items] and language of morphological relation $[F(1,37)$ $=46.24, M S_{\mathrm{e}}=2,071.31, p<.001$, for subjects; $F(1,48)=15.96, M S_{\mathrm{e}}=3,831.47, p<.001$, for items]. The effect of condition reflected faster RTs for primed than unprimed trials, and the effect of language reflected faster RTs for the trials in the English + ASL stimulus set.

An analysis of the errors on words indicated only a significant effect of language in the subjects analysis $\left[F(1,37)=4.34, M S_{\mathrm{e}}=14.81, p<.05\right]$, reflecting somewhat fewer errors on the words used in the English + ASL set than on those in the ASL-only set. This effect was only marginally significant in the items analysis $\left[F(1,48)=3.64, M S_{\mathrm{e}}=19.79, p<.07\right]$.

In studies of repetition priming, the data from the nonword trials can be used as an index of whether the obtained facilitation is due to an experiment-specific (episodic) effect or to a lexical effect (Feustel, Shiffrin, \& Salasoo, 1983; Fowler et al., 1985). Nonword facilitation is generally not considered to be lexical in origin. If significant facilitation is obtained in the nonword data, then episodic, rather than lexical, influences might also contribute to the outcome observed with words. The mean correct RTs and mean percentage errors for the nonwords are shown in Table 2 . In the analysis of nonword RTs, the only significant finding was an interaction of prime condition $\times$ language of morphological relation in the subjects analysis $\left[F(1,37)=5.59, M S_{\mathrm{e}}=3,049.80\right.$, $p<.05]$. This effect failed, however, to reach significance in the items analysis $\left[F(1,52)=.16, M S_{\mathrm{e}}=\right.$ $1,912.771$, indicating that the effect in the subjects analysis was due to a couple of problematic stimuli. In the analysis of the nonword error data, there was a significant effect of prime condition $\left[F(1,37)=5.73, M S_{\mathrm{e}}=\right.$ $135.21, p<.05]$ and a significant interaction of prime condition $\times$ language of morphological relation $[F(1,37)$ $\left.=4.25, M S_{e}=132.05, p<.05\right]$, neither of which reached statistical significance in the items analysis ( $F$ s $<1$ for both). The nonword data, therefore, give little reason to infer that episodic influences contribute to the pattern of results obtained for the word data.

\section{Discussion}

The same pattern of results was observed for the hearing subjects and the deaf subjects in the English lexical decision task; that is, there was an interaction of prime condition $\times$ language of morphological relation such that significant facilitation was obtained only for prime-target pairs that were related in English. The significant facilitation with the English + ASL materials replicates earlier work by Hanson and Wilkenfeld (1985), namely, significant facilitation for targets preceded by primes that were morphologically related in both languages. The finding of interest in the present experiment is the absence of facilitation on trials in which ASL provided the only relationship of prime to target. This pattern of results suggests that the lexical organization of English materials by deaf readers is based on morphological relationships that are evident in English, not on those present in ASL. Thus, the lexical organization of these signers tends to be language specific, in that processing of ASL involves a structuring based on principles of ASL morphology, and processing of English involves a structuring based on English morphology.

The subjects' better performance on the English + ASL set than on the ASL-only set, as indicated by faster RTs and fewer errors, cannot be interpreted as reflecting an inherent difference in cognitive processing for English and ASL. Rather, this effect simply reflects the subjects' differential familiarity with words in the two sets. During stimulus creation, these two sets were not equated for word frequency or familiarity.

\section{GENERAL DISCUSSION}

Important to our interpretation of language specificity in lexical organization are the different patterns of facilitation for the ASL-only morphologically related primetarget pairs in Experiments 1 and 2 . In a task that required decisions on words of English (the lexical decision task of Experiment 2), the deaf subjects were not facilitated in their responding to pairs that were morphologically related only in ASL. In a task that required decisions on signs of ASL, however (the sign decision task of Experiment 1), the deaf subjects' responses were facilitated when prime-target pairs were related in ASL. To be able to conclude that the obtained facilitation reflects the ASL relatedness of the noun-verb pairs, it is necessary to rule out possible explanations of this effect that attribute it to 
the associative relatedness of the signs in the ASL-only set or, alternatively, to the visual/motoric similarity of those signs.

Inasmuch as the pairs in the ASL-only set were associatively related, it bears considering whether the facilitation in Experiment 1 could be attributed to associative relatedness. To begin, we can use the pattern of facilitation across experiments to dismiss an account based on associative priming. In the ASL-only set, response facilitation occurred in the sign decision task of Experiment 1, in which responses were based on signs of ASL, but not in the lexical decision task of Experiment 2, in which responses were based on words of English. Had associative factors been responsible for the outcomes in Experiment 1, they should have been evident in Experiment 2 as well. It could be argued that such reasoning across experiments does not apply in the present case, because different tasks were used in the two experiments. Although there is evidence that some priming tasks produce associative priming whereas others do not (Henik, Friedrich, \& Kellogg, 1983; Smith, Theodor, \& Franklin, 1983), priming effects have been obtained only over lags of 1 or 2 items, even with tasks favorable to associative priming (Henik et al., 1983; Meyer, Schvaneveldt, \& Ruddy, 1975; Ratcliff et al., 1985; Rugg, 1987; Smith et al., 1983; see also Dannenbring \& Briand, 1982). The lag of 10 items in Experiment 1 is clearly beyond that at which associative priming can be expected to persist.

As discussed above, an account of Experiment 1 based on formal priming (i.e., physical similarity) is also inadequate. Because of the difficulty in demonstrating facilitation based on the formal similarity of prime and target in several lexical decision and recognition tasks at comparable (or longer) lags (Feldman \& Moskovljević, 1987; Hanson \& Wilkenfeld, 1985; Murrell \& Morton, 1974) or even at shorter lags (Napps \& Fowler, 1987), we conclude that formal similarity could not have governed the outcome in the sign decision task of Experiment 1.

Thus, the facilitation on the prime-target pairs that were morphologically related only in ASL in Experiment 1 can be attributed to lexical organization based on ASL. The absence of facilitation in the English lexical decision task for deaf subjects on the prime-target pairs that were morphologically related only in ASL suggests that the English lexicons of these signers is not organized according to relationships inherent to ASL. How are their English lexicons organized? We know from previous research that the English lexicons of deaf skilled readers are not organized visually/orthographically (Hanson \& Wilkenfeld, 1985 ). Since the evidence of the present study indicates that it is not organized along principles of ASL morphology, the obtained facilitation in the present experiment and the earlier work on repetition priming with deaf readers (Hanson \& Wilkenfeld, 1985) suggests that for deaf skilled readers, the English lexicon is organized along a principle of English morphology.

The present evidence that principles of ASL morphology influence how deaf skilled readers process ASL signs but not how they process individual words of English is inconsistent with the primary-language notion suggested by Shand (1982; Shand \& Klima, 1981). Although the exact meaning of "primary language" as used by Shand has always been vague, the basic assumption is that the language processing of deaf signers will be carried out in sign, regardless of whether the language input is sign or print. This notion clearly predicts that deaf signers will show a tendency to process printed English words in terms of their sign equivalents, something not found here.

In understanding the results of the present study, it is necessary to recall that the subjects of the study were quite skilled deaf readers. As noted earlier, they may not be representative of all deaf signers in that the average of their reading scores was exceptionally high. This leaves open the possibility that less skilled deaf readers might perform differently than the subjects who participated in the present study. It is still possible, therefore, that the primary-language notion may better describe the English processing of less skilled deaf readers.

In conclusion, the outcome of Experiment 2 revealed no evidence that the lexical organization of English is influenced by characteristics of ASL. It should be recalled, however, that in Experiment 1 evidence was obtained for lexical organization based on ASL morphology in a task that required a decision based on signs of ASL. This pattern of results suggests that deaf skilled readers use morphological principles of ASL in their lexical organization of ASL, but that their lexical organization of English does not reflect morphological characteristics of ASL. In sum, lexical organization is language specific.

\section{REFERENCES}

Beauvillain, C., \& Grainger, J. (1987). Accessing interlexical homographs: Some limitations of a language-selective access. Journal of Memory \& Language, 26, 658-672.

Dannenbring, G. L., BRiand, K. (1982). Semantic priming and the word repetition effect in a lexical decision task. Canadian Journal of Psychology, 36, 435-444.

Feldman, L. B. (1987). Phonological and morphological analysis by skilled readers of Serbo-Croatian. In A. Allport, D. MacKay, W. Prinz, \& E. Scheerer (Eds.), Language perception and production (pp. 197-209). London: Academic Press.

Feldman, L. B., \& Moskovluević, J. (1987). Repetition priming is not purely episodic in origin. Journal of Experimental Psychology: Learning, Memory, \& Cognition, 13, 573-581.

Feustel, T. C., Shiffrin, R. M., \& Salasoo, A. (1983). Episodic and lexical contributions to the repetition effect in word identification. Journal of Experimental Psychology: General, 112, 309-346. Fowler, C. A., NapPS, S. E., \& Feldman, L. B. (1985). Relations among regular and irregular morphologically related words in the lexicon as revealed by repetition priming. Memory \& Cognition, 13, 241-255.

Gates-MacGinitie Reading Tests (2nd ed., 1978). Boston: Houghton Mifflin

Hanson, V. L., \& Bellugi, U. (1982). On the role of sign order and morphological structure in memory for American Sign Language sentences. Journal of Verbal Learning \& Verbal Behavior, 21, 621-633.

Hanson, V. L., \& Wilkenfeld, D. (1985). Morphophonology and lexical organization in deaf readers. Language \& Speech, 28, 269-280.

Henderson, L., Wallis, J , \& Knight, D. (1984). Morphemic structure and lexical access. In H. Bouma \& D. H. Bouwhuis (Eds.), Attention and performance $X$ : Control of language processes (pp. 211226). London: Erlbaum.

HeniK, A., Friedrich, F. J., \& Kellogo, W. (1983). The dependence 
of semantic relatedness effects upon prime processing. Memory \& Cognition, 11, 366-373.

Kirsner, K., Brown, H. L., Abrol, S., Chadha, N. N., \& Sharma, N. K. (1980). Bilingualism and lexical representation. Quarterly Journal of Experimental Psychology, 32, 585-594.

Kirsner, K., DUnN, J., \& STANDEN, P. (1987). Record-based word recognition. In M. Coltheart (Ed.), Attention and performance XII (pp. 147-167). London: Erlbaum.

Kirsner, K., Smith, M. C., Lockhart, R. S., King, M. L., \& J AIN, M. (1984). The bilingual lexicon: Language-specific units in an integrated network. Joumal of Verbal Learning \& Verbal Behavior, 23, 519-539.

Kroll, J. F., \& Borning, L. (1987, November). Shifting language representations in novice bilinguals: Evidence from sentence priming. Paper presented at the meeting of the Psychonomic Society, Seattle, WA.

Lukatela, G., Gligorijević, B., Kostić, \& Turvey, M. T. (1980). Representation of inflected nouns in the internal lexicon. Memory \& Cognition, 8, 415-423.

Meyer, D. E., Schyaneveldt, R. W., \& Ruddy, M. G. (1975). Loci of contextual effects on visual word recognition. In P. M. A. Rabbitt and S. Dornic (Eds.), Attention and performance $V$ (pp. 98-118). London: Academic Press.

MurRell, G. A., \& Morton, J. (1974). Word recognition and morphemic structure. Journal of Experimental Psychology, 102, 963-968.

NAPPS, S. E., \& FowlER, C. A. (1987). Formal relationships among words and the organization of the mental lexicon. Joumal of Psycholinguistic Research, 16, 257-272.

PAdden, C. A. (1987). Grammatical theory and signed languages. In F. Newmeyer (Ed.), Linguistics: The Cambridge Survey (pp. 250266). Cambridge: Cambridge University Press.

Poizner, H., Bellugi, U., \& Tweney, R. D. (1981). Processing of formational, semantic, and iconic information in American Sign Language. Journal of Experimental Psychology: Human Perception \& Performance, 7, 1146-1159.

Poizner, H., Klima, E. S., \& Bellugi, U. (1987). What the hands reveal about the brain. Cambridge, MA: Bradford Books/MIT Press.

Poizner, H., Newkirk, D., Bellugi, U., \& Klima, E. S. (1981). Representation of inflected signs from American Sign Language in short-term memory. Memory \& Cognition, 9, 121-131.

RATCLif, R., HockLeY, W., McKoon, G. (1985). Components of activation: Repetition and priming effects in lexical decision and recognition. Journal of Experimental Psychology: General, 114, 435450.

RUGG, M. D. (1987). Dissociation of semantic priming, word and nonword repetition effects by event-related potentials. Quarterly Journal of Experimental Psychology, 39, 123-148.

Scarborough, D. L., Gerard, L., \& Cortese, C. (1984). Indepen- dence of lexical access in bilingual word recognition. Journal of Verbal Learning \& Verbal Behavior, 23, 84-99.

Shand, M. A. (1982). Sign-based short-term memory coding of American Sign Language signs and printed English words by congenitally deaf signers. Cognitive Psychology, 14, 1-12.

Shand, M. A., \& KLima, E. S. (1981). Nonauditory suffix effects in congenitally deaf signers of American Sign Language. Journal of Experimental Psychology: Human Learning \& Memory, 12, 464-474.

SмIтH, C. R. (1975). Residual hearing and speech production in deaf children. Journal of Speech \& Hearing Research, 18, 759-811.

Smith, M. C., Theodor, L., \& Franklin, P. E. (1983). The relationship between contextual facilitation and depth of processing. Journal of Experimental Psychology: Learning, Memory, \& Cognition, 9, 697-712.

Stanners, R. F., Neiser, J. J., Hernon, W. P., \& Hall, R. (1979). Memory representation for morphologically related words. Journal of Verbal Learning \& Verbal Behavior, 18, 399-412.

Stokoe, W. C., Jr., Casterline, D., Croneberg, C. (1965). A dictionary of American Sign Language. Washington, DC: Gallaudet College Press.

Supalla, T., \& NewPort, E. (1978). How many seats in a chair? The derivation of nouns and verbs in American Sign Language. In P. Siple (Ed.), Understanding language through sign language research (pp. 91-132). New York: Academic Press.

TAFT, M., \& FoRSTER, K. I. (1975). Lexical storage and retrieval of prefixed words. Journal of Verbal Learning \& Verbal Behavior, 14, 638-647.

W Atxins, M. J., \& Peynircioğlu, Z. F. (1983). On the nature of word recall: Evidence for linguistic specificity. Journal of Verbal Learning \& Verbal Behavior, 22, 385-394.

\section{NOTES}

1. In the case of two stimuli, SAIL and $L I C K$, the ASL signs are usually translated as GO BY BOAT and LICK ICE CREAM (Supalla \& Newport, 1978). Given the consistency of the subjects and items analyses in Experiments 1 and 2, these deviations from the exact translations do not appear to have caused problems.

2. The term phonological need not be limited to use with spoken languages. In the case of ASL, for example, the term phonology has been used to describe the linguistic primitives related to the visible gestures articulated by the hands, face, and body of the signer.

3. Experiments 1 and 2 were run in reverse order. The changes in the English + ASL set were necessary in order to have approximately equal numbers of one- and two-handed sign responses in Experiment 1.

4. The morphological prime $K E Y$ was incorrectly typed as $K I N G$ in the stimulus list shown in Experiment 2 only. The target word LOCK was therefore omitted from analysis in this experiment.

\section{APPENDIX}

\begin{tabular}{|c|c|c|c|}
\hline \multicolumn{2}{|c|}{ English + ASL } & \multicolumn{2}{|c|}{ ASL only } \\
\hline Target & Morphological Prime & Target & Morphological Prime \\
\hline \multicolumn{4}{|c|}{ Experiment 1} \\
\hline WISH & WISHING & EAT & FOOD \\
\hline CRASH & CRASHED & SAIL & BOAT \\
\hline WALK & WALKED & SHOOT & GUN \\
\hline CREATE & CREATING & TELEPHONE & CALL \\
\hline HELP & HELPER & BROOM & SWEEP \\
\hline COMPLAIN & COMPLAINING & WAITRESS & SERVE \\
\hline DEMAND & DEMANDED & DRIVE & CAR \\
\hline RELAX & RELAXED & CHAIR & SIT \\
\hline JUMP & JUMPING & LOCK & KEY \\
\hline KILL & KILLER & SCISSORS & CUT \\
\hline TEACH & TEACHER & ICE CREAM & LICK \\
\hline BORROW & BORROWED & SHOVEL & DIG \\
\hline RIDE & RIDER & LAWNMOWER & MOW \\
\hline LOVE & LOVER & STRUM & GUITAR \\
\hline
\end{tabular}


APPENDIX (Continued)

\begin{tabular}{llll}
\hline \multicolumn{2}{c}{ English + ASL } & \multicolumn{2}{c}{ ASL only } \\
\cline { 4 - 4 } Target & Morphological Prime & \multicolumn{1}{c}{ Target } & Morphological Prime \\
HELP & HELPER & Experiment 2 & \\
TURN & TURNING & EAT & FOOD \\
CRASH & CRASHES & SAIL & BOAT \\
WALK & WALKER & TELEPHONE & CALL \\
DEMAND & DEMANDED & BROOM & SWEEP \\
HANDLE & HANDLER & WAITRESS & SERVE \\
CREATE & CREATES & DRIVE & CAR \\
RELAX & RELAXED & CHAIR & SIT \\
LOVE & LOVER & LOCK & KEY \\
SLEEP & SLEEPER & SCISSORS & CUT \\
NEED & NEEDED & ICE CREAM & LICK \\
RIDE & RIDER & SHOVEL & DIG \\
JUMP & JUMPING & LAWNMOWER & MOW \\
CREDIT & CREDITOR & STRUM & GUITAR \\
\hline & & & \\
& \multicolumn{2}{c}{ (Manuscript received March 10, 1988; } & \\
& revision accepted for publication August 10, 1988.) &
\end{tabular}

